\title{
Coronary artery plaque burden and calcium scores in healthy men adhering to long-term wine drinking or alcohol abstinence
}

\author{
P.L. da Luz ${ }^{1}$, S. Coimbra ${ }^{1}$, D. Favarato ${ }^{1}$, C. Albuquerque ${ }^{1}$, R.I. Mochiduky ${ }^{2}$, C.E. Rochitte ${ }^{2}$ \\ E. Hojaij ${ }^{3}$, C.R.L. Gonsalves ${ }^{4}$ and F.R. Laurindo ${ }^{5}$
}

${ }^{1}$ Divisão de Cardiologia Clínica, Instituto do Coração (Incor), Faculdade de Medicina, Universidade de São Paulo, São Paulo, SP, Brasil ${ }^{2}$ Divisão de Radiologia, Instituto do Coração (Incor), Faculdade de Medicina, Universidade de São Paulo, São Paulo, SP, Brasil

${ }^{3}$ Serviço de Psicologia, Instituto do Coração (Incor), Faculdade de Medicina, Universidade de São Paulo, São Paulo, SP, Brasil ${ }^{4}$ Serviço Nutricional, Instituto do Coração (Incor), Faculdade de Medicina, Universidade de São Paulo, São Paulo, SP, Brasil

${ }^{5}$ Laboratório de Biologia Vascular, Instituto do Coração (Incor), Faculdade de Medicina, Universidade de São Paulo, São Paulo, SP, Brasil

\begin{abstract}
Observational studies suggest there are clinical benefits to moderate red wine (RW) consumption. However, the effects on coronary vasculature and overall lifestyle are unclear. We investigated whether a lifestyle of regular long-term RW consumption is associated with changes in coronary plaque burden, calcium score, carotid intima/media thickness, endothelial function, and metabolic variables, compared with alcohol abstinence. Healthy volunteers were evaluated by coronary computed tomography angiography (CTA) as well as carotid and brachial artery ultrasound. Nutritional status, psychological status, and metabolic variables were assessed. The study included 101 drinkers [aged $58.9 \pm 7.3$ years (means \pm SD)], from wine brotherhoods, and 104 abstainers, from Anglican, Evangelical and Catholic churches both in the city of São Paulo, Brazil. No significant differences in demographics were noted. Lesion prevalence per patient assessed by coronary CTA and classified as absent (0), $1-25,26-49$, and $\geqslant 50 \%$ stenosis was similar between groups. When analyzed by individual arteries, i.e., left anterior descending, circumflex, and right coronary, prevalence was also not different. On the other hand, calcium scores were higher among drinkers than abstainers $(144.4 \pm 362.2$ vs $122.0 \pm 370.3 ; \mathrm{P}<0.01)$. However, drinkers reported less history of diabetes and exercised more. RW drinkers consumed $2127.9 \pm 387.7 \mathrm{kcal} /$ day while abstainers consumed $1836.0 \pm 305.0(\mathrm{P}<0.0001)$. HDL cholesterol was significantly higher among drinkers compared to abstainers $(46.9 \pm 10.9 \mathrm{vs} 39.5 \pm 9.0 \mathrm{mg} / \mathrm{dL}$; $\mathrm{P}<0.001)$, while fasting plasma glucose was lower $(97.6 \pm 18.2$ vs $118.4 \pm 29.6 \mathrm{mg} / \mathrm{dL} ; \mathrm{P}<0.02)$. Liver enzymes were normal in both groups. In conclusion, long-term wine drinkers displayed a similar plaque burden but greater calcium score than abstainers, despite a more atherogenic diet, and the mechanisms for the increased calcium scores in the former remain speculative.
\end{abstract}

Key words: Atherosclerosis; Red wine; Lifestyle; Computer tomography angiography; Coronary calcium; Carotid plaques

\section{Introduction}

Several clinical studies $(1,2)$ documented the beneficial effects of red wine (RW) consumption and alcohol in general. For instance, a recent metanalysis (3) that included 84 cohort studies with a median follow-up of 11 years documented an average $25 \%$ risk reduction in cardiovascular mortality and mortality due to coronary artery disease (CAD) among light to moderate alcohol drinkers compared to abstainers. Another metanalysis (4), focusing specifically on RW, included 13 prospective and case-control studies and documented similar benefits on vascular risk. Furthermore, in the cardiovascular health study (5), a lower risk of incident heart failure was documented among older adults who consumed moderate amounts of alcohol compared to abstainers. Several experimental studies (6-8), in different animal models, indicate that RW polyphenols are vasodilators, antithrombotic, antioxidants, prolong life in rats fed a high-fat diet (9), increase telomerase, and preserve telomere length in normal rats (10), thus providing mechanistic support for the protective actions of RW.

However, few data are available regarding total plaque burden or coronary calcium scores in chronic drinkers.

Correspondence: P.L. da Luz, Instituto do Coração, Hospital das Clínicas, Faculdade de Medicina, Universidade de São Paulo, Avenida Dr. Enéas de Carvalho Aguiar, 44, 5을. andar, Bloco II, Sala 8, 05403-000 São Paulo, SP, Brasil. E-mail: protasio.luz@incor.usp.br 
Most previous studies focused on clinical parameters, or surrogate markers of atherosclerosis, such as carotid intima/media thickness (IMT) (11) and endothelial function (12). Yet plaque burden, plaque composition, and calcium score are fundamental determinants of clinical evolution. Recently, Motoyama et al. (13) identified positive remodeling and the presence of soft tissue as markers of unstable plaques in coronary computed tomography angiography (CTA). In their study, unstable plaques were indeed associated with acute events.

Therefore, in this cross-sectional study we compared plaque burden, coronary calcium score, carotid IMT, endothelial function, several indicators of lifestyle, and metabolic parameters in long-term RW drinkers and abstainers. In contrast to many previous studies in which several kinds of beverage were considered as sources of alcohol (14), we focused on people who are preferentially wine drinkers.

\section{Material and Methods}

Two hundred and five selected healthy male volunteers, 50 to 75 years of age, were studied. One hundred and one volunteers belonged to wine brotherhoods and were considered to be drinkers, i.e., they consumed at least one glass of RW, 4-5 days/week, in the 5 years preceding the beginning of the study. One hundred and four volunteers belonged to Anglican, Evangelical, and Catholic churches and were considered to be abstainers who did not drink any alcohol at all. All participants signed an informed consent form, and the protocol was approved by the Ethics Committee of Instituto do Coração, Universidade de São Paulo, Brazil.

A detailed medical history and physical examination were performed for each subject. Diagnostic criteria for cardiovascular risk factors were as follows: glucose intolerance; fasting glycemia between $100 \mathrm{mg}$ and $125.9 \mathrm{mg} / \mathrm{L}$; diabetes, fasting glucose $\geqslant 126 \mathrm{mg} / \mathrm{dL}$ or patient already taking oral anti-diabetic drugs and/or insulin; hypercholesterolemia, if total cholesterol (TC) was $>200 \mathrm{mg} / \mathrm{dL}$ or LDL-cholesterol $>130 \mathrm{mg} / \mathrm{dL}$; low $\mathrm{HDL}$-cholesterol, if $\mathrm{HDL}<40 \mathrm{mg} / \mathrm{dL}$; hypertriglyceridemia, if triglyceride (TG) $>150 \mathrm{mg} / \mathrm{dL}$; hypertension was arbitrarily defined as blood pressure $>130 / 80 \mathrm{mmHg}$ or the patient was already using anti-hypertensive medications; smoking, if patients were current smokers; sedentary lifestyle, when subjects did not engage in any physical training program or regular sports practice. Sedentary lifestyle or sedentarism was defined as exercise $<150 \mathrm{~min} /$ week.

Abdominal obesity was defined as having a waist circumference $>100 \mathrm{~cm}$; overweight was defined as body mass index (BMI) ranging from 25.1 to $29.9 \mathrm{~kg} / \mathrm{m}^{2}$; and obesity was defined as BMI $\geqslant 30.0 \mathrm{~kg} / \mathrm{m}^{2}$. Positive family history for cardiovascular disease was considered when one or more immediate relatives had suffered a myocardial infarction, acute coronary syndrome, coronary angioplasty, or coronary artery bypass grafting.

Regarding income, participants were classified as having monthly earnings of $<5$ times the minimum wage, 5 to 10 times the minimum wage, and $>10$ times the minimum wage in Brazilian currency $(1 \mathrm{USD}=1.85 \mathrm{BRL})$. Education was rated as illiteracy, incomplete basic, basic, median, and superior. Quality of life was assessed using SF-36 and the WHOQOL-BREF scales (15), stress using the Inventory of Stress Symptoms of Lipp (ISSL) (16), personality using the Comrey scale (17), and depression and anxiety using the respective Beck inventories (18) all applied by experienced psychologists.

Nutritional status was evaluated by a food questionnaire over 3 days/week, as previously described (19). Total caloric consumption was estimated, as well as carbohydrates, proteins, total fat, saturated fat, poly- and monounsaturated fats, and fiber. Alcohol consumption also was estimated.

Brachial artery reactivity was assessed with a 7.5$\mathrm{MHz}$ linear array vascular transducer from an APOGEE 800 plus ATL ultrasound system (ATL Ultrasound, USA). Flow-mediated dilation (FMD) and responses to $5 \mathrm{mg}$ sublingual isosorbide dinitrate were assessed as described under current guidelines $(20,21)$. All tests were performed blind and were analyzed by a single experienced ultrasonographer. Carotid IMT of both right and left common carotid arteries were measured by trained technicians; three to six measurements were obtained from each artery and then averaged, and the presence of atherosclerotic plaques - defined as localized thickness $>1 \mathrm{~mm}$ - was also recorded. Images were examined in a blind fashion.

\section{Coronary CTA}

Multiple detection of coronary CTA was performed in an Aquillion One 320 scanner (Toshiba Medical Systems, Japan) using a single cardiac beat, prospective acquisition mode. This volumetric acquisition had a temporal resolution of $165 \mathrm{~ms}$, collimation $320 \times 0.5 \mathrm{~mm}$, and spatial resolution of $0.3 \mathrm{~mm}$ thick slices as previously described (22). Tube current and voltage were modulated based on the patient's body habitus by an automated algorithm (AIRD-3D). Calcium score image acquisition used prospective acquisition with 3-mm thick slices. An Agatston score was used for calcium quantification.

Coronary lesions were classified as absent ( 0 stenosis), $1-25,26-49$, and $\geqslant 50 \%$ stenosis in the right (RCA), left anterior descending (LAD), and circumflex (LCX) coronary artery territories, encompassing proximal, medial, and distal portions; LAD territory included diagonals, LCX incorporated marginals and RCA, marginals plus posterior descending and ventricular; left main was also considered. Accordingly, 16 coronary segments were examined in each individual for a total of 3280 segments. 
CTAs were read by the same investigator (RIM), in blinded fashion. When in doubt, a second opinion was obtained (CER). Based on the study by Motoyama et al. (13), vulnerable plaques were identified when two of the following were present: a) positive remodeling, i.e., a $10 \%$ increment in diameter relative to the segment proximal to the lesion; and $b$ ) plaques with low attenuation, i.e., less than 30 Hounsfield units (HU), which indicated increased lipid content. Vulnerable plaques were identified based on a color-coding system and corresponding $\mathrm{HU}$. In this system, white bright color corresponds to calcium, designated as $+1000 \mathrm{HU}$, and totally black corresponds to $-1000 \mathrm{HU}$.

Plasma TC, HDL-cholesterol, TG, and glucose were determined by enzymatic methods (Roche Laboratories, Switzerland). LDL-cholesterol was measured by enzymatic methods (Study 28, Roche Laboratories) or estimated by the Friedewald's formula. Bilirubin, aspartate aminotransferase, alanine aminotransferase, gamma glutamyl transferase ( $\gamma$-GT), alkaline phosphatase, urea, and creatinine were analyzed with specific kits for automated Dimension RXL equipment (Siemens Healthcare Global, USA). $\mathrm{Na}^{+}$and $\mathrm{K}^{+}$were obtained using selective electrodes in Dimension RXL equipment. Ultrasensitive $C$ reactive protein (usCRP) was measured with a CardioPhase ${ }^{\mathbb{R}}$ hsCRP kit in the BN II System, Siemens Healthcare Global (Germany). Prostatic serum antigen (PSA) levels were obtained by immunometric assay in automated Immulite 2000 equipment (Siemens Healthcare Global). Complete blood and platelet counts were determined by standard methods.

\section{Protocol}

Subjects came to the laboratory early in the morning, after a 12-h fast, and were subjected to physical examination, venous blood collection, and endothelial and carotid studies. They ate a light lunch, and were then subjected to CTA. Psychological tests were performed on the same day, and they were instructed to respond to a nutritional questionnaire by a trained nutritionist. Upon completion of the tests, a formal report was sent to each participant with recommendation that a copy should be conveyed to their attending physicians.

\section{Statistical analysis}

Categorical variables are reported by frequency count and percentage, and continuous variables by means and standard deviation (SD). Comparisons between the two groups were carried out by the chi-square test for categorical variables or $t$-test for continuous variables. An initial exploratory univariate analysis was carried out including all demographic, laboratory, diet, and lifestyle variables in relation to lesion burden and calcium score. Variables that displayed $\mathrm{P}<0.2$ were then entered into a multivariate analysis by logistic regression for abnormal calcium and lesions in coronary arteries.

\section{Results}

\section{Demographics}

Age was not different between the groups (59.5 \pm 7.7 vs $58.5 \pm 7.0$ years); blood pressure, race, abdominal circumference, and BMI were also not different; however, BMI was slightly higher than normal, averaging $28.5 \pm 3.8$ among drinkers and 28.2 \pm 4.1 among abstainers (Table 1). Also, heart rate was slightly higher in abstainers than smokers, but within normal ranges.

\section{Coronary lesions and calcium scores}

Figure $1 \mathrm{~A}$ shows the frequency of coronary lesions per patient classified as absent (0), 1-25, 26-49, and $\geqslant 50 \%$ obstructions, in 16 coronary segments per patient. There were no significant differences between the groups. Figure 1B shows the frequency of coronary lesions in LAD, LCX, and RCA territories, which also was similar by the chi-square test.

Variables with $\mathrm{P}<0.2$ in the univariate analysis were entered into a logistic regression multivariate analysis, which included fasting glucose, age, TGs, and TG/HDL ratio; only fasting glucose and age correlated with the presence of $\geqslant 50 \%$ lesions. When considering the presence of any coronary lesion, age, fasting glucose, and non-HDL cholesterol correlated with the appearance of lesions. Vulnerable plaques, as assessed by Motoyama's technique, were found in $6.2 \%$ of drinkers and $11.6 \%$ of abstainers, but this difference was not statistically significant. Two individuals, one in each group, displayed severe coronary lesions and were subjected to coronary bypass surgery.

The average Agatston calcium score was significantly higher in RW drinkers compared to abstainers $(144.4 \pm 362.2$ vs $122.0 \pm 370.3$ units; $P<0.01)$. Figure $1 \mathrm{C}$ shows quartiles of age-adjusted calcium scores. It can be seen that the difference was due to a higher percentage of zero calcium among abstainers compared to RW drinkers (55.1 vs 33.7\%; $\mathrm{P}<0.007)$. Quartiles adjusted for age were not significantly different.

By logistic regression multivariate analysis, which included wine, usCRP, systolic blood pressure, TC, TG, waist circumference, and glucose, only RW ingestion and age were significantly associated with a calcium score $>100$; this score was chosen because it is considered clinically relevant and indicates a significant atherosclerotic burden.

\section{Brachial artery reactivity and carotid studies}

FMD and nitrate dilation in the brachial artery were not different between the groups (Table 2). Similarly, IMT of both right and left common carotid arteries was comparable between the groups; and atherosclerotic plaques were found in $6 \%$ of drinkers and $5 \%$ of abstainers.

\section{Laboratory values}

Metabolic variables are reported in Table 3. TC and 
Table 1. Demographic characteristics.

\begin{tabular}{|c|c|c|c|}
\hline Variable & Red wine & Abstainers & $\mathrm{P}$ \\
\hline Number & 101 & 104 & \\
\hline Age (years) & $59.5 \pm 7.7$ & $58.5 \pm 7.0$ & ns \\
\hline \multicolumn{4}{|l|}{ Race } \\
\hline Caucasian & $97 \%$ & $81 \%$ & ns \\
\hline Black & $1 \%$ & $11 \%$ & ns \\
\hline Non-Caucasian & $2 \%$ & $9 \%$ & ns \\
\hline BMI $\left(\mathrm{kg} / \mathrm{m}^{2}\right)$ & $28.5 \pm 3.8$ & $28.2 \pm 4.1$ & ns \\
\hline Waist $(\mathrm{cm})$ & $100.2 \pm 10.7$ & $98.8 \pm 11.3$ & ns \\
\hline Waist/Hip & $0.94 \pm 0.05$ & $0.95 \pm 0.06$ & ns \\
\hline Systolic blood pressure $(\mathrm{mmHg})$ & $134.5 \pm 16.8$ & $137.0 \pm 16.5$ & ns \\
\hline Diastolic blood pressure $(\mathrm{mmHg})$ & $83.8 \pm 11.1$ & $84.9 \pm 9.2$ & ns \\
\hline Heart rate (bpm) & $65.7 \pm 9.5$ & $68.9 \pm 10.3$ & 0.023 \\
\hline \multicolumn{4}{|l|}{ Risk factors } \\
\hline Hypertension (\%) & $37(37.0)$ & $47(45.0)$ & ns \\
\hline Diabetes mellitus (\%) & $4(4.0)$ & $17(16.3)$ & 0.0056 \\
\hline Current smokers (\%) & $8(7.9)$ & $5(3.6)$ & ns \\
\hline Former smokers (\%) & $22(21.8)$ & $7(6.7)$ & 0.0038 \\
\hline Sedentarism (\%) & $27(26.7)$ & $58(55.8)$ & $<0.0001$ \\
\hline Obesity $\left(\mathrm{BMI}>30 \mathrm{~kg} / \mathrm{m}^{2}\right)(\%)$ & $26(25.7)$ & $32(30.7)$ & ns \\
\hline Family history $\mathrm{CHD}$ & $13(13.0)$ & $13(12.5)$ & ns \\
\hline $\mathrm{CHD}$ & 1 & 0 & ns \\
\hline
\end{tabular}

Data are reported as means \pm SD unless otherwise indicated. BMI: body mass index; CHD: coronary heart disease; ns: not significant The chi-square test was used for statistical analyses.

HDL were higher among drinkers $(\mathrm{P}<0.001)$ and plasma glucose was lower $(\mathrm{P}<0.02)$ compared to abstainers. The inflammatory marker usCRP, renal function, other lipids, and PSA were comparable. $\gamma$-GT was higher in RW drinkers and alkaline phosphatase was higher in abstainers, but all liver enzymes remained within normal values, even though drinkers consumed RW for an average of $18.0 \pm 10.2$ years.

\section{Lifestyle characteristics}

As shown in Table 4, in general, RW drinkers had higher income, e.g., there were fewer individuals with the lowest income and more with higher incomes than among abstainers $(P<0.0001)$. Also, among drinkers there was a lower percentage of individuals with lower education and a higher percentage with superior education than among abstainers $(P<0.0001)$. Similarly, drinkers exercised more per week than abstainers, and fewer of them were sedentary $(\mathrm{P}<0001$; all by chi-square tests).

There were significant differences regarding diet (Table 4). RW drinkers reported ingesting more calories per day than abstainers $(2127 \pm 387.7$ vs $1836.0 \pm 305.0 \mathrm{kcal}$; $\mathrm{P}<0.0001)$; this was mainly due to higher amounts of protein, total fat, saturated fats, and poly- and monounsaturated fats, since carbohydrates were similar. In contrast, dietary fiber was higher among abstainers than drinkers $(22.6 \pm 7.0$ vs $19.6 \pm 6.4 \mathrm{~g} ; \mathrm{P}<0.052)$. In addition, of course, drinkers reported consuming about $25 \mathrm{~g}$ of alcohol daily as RW, while abstainers did not drink at all.

As far as risk factors are concerned, the frequency of diabetes was higher among abstainers (17\% vs $4 \%$; $\mathrm{P}=0.005)$; but history of hypertension, smoking, sedentarism, previous coronary heart disease, and positive family history for CAD were all similar.

\section{Discussion}

In this study, we observed that long-term RW drinkers had a similar coronary plaque burden but higher calcium scores, higher HDL, less of a previous history of diabetes, and lower plasma glucose than abstainers. Also, no significant differences were observed regarding carotid IMT and endothelial function.

The effect of RW ingestion on coronary lesions, which was the major objective of the study, deserves comment. The extent of coronary lesions was very similar between the two groups, with the exception of zero lesions in LCX. Given that drinkers consumed a more atherogenic diet, especially as fats and proteins, and that they reported more previous history of smoking, but did not have more extensive coronary lesions than abstainers, it is tempting to admit a protective effect of RW on lesion burden, and such an effect could be due to the action of HDL and glucose as mentioned earlier (6). In fact, fasting glucose, 

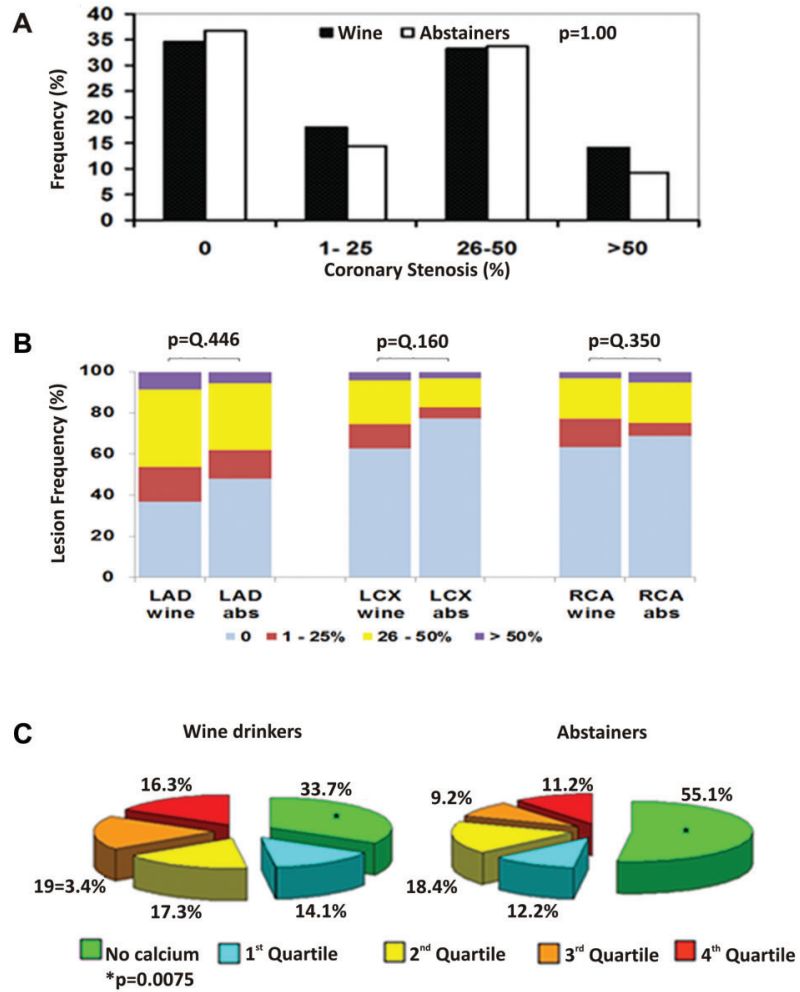

Figure 1. $A$, Frequency of coronary lesions/patient, classified as absent (0 stenosis), 1-25, 26-49, and $\geqslant 50 \%$, encompassing 16 segments/patient, in red wine (RW) drinkers and abstainers (Abs). No significant differences were found. $B$, Frequency of coronary lesions in LAD, LCX and RCA territories (0; blue), $1-25 \%$ (green), $1-49 \%$ (yellow), and $\geqslant 50 \%$ stenosis (red). Sixteen coronary segments were analyzed in each individual by computed coronary angiography. There were no significant differences between the groups, except for 0 lesions in LCX, which were more frequent among abstainers. LAD: left anterior descending artery; LCX: left circumflex coronary artery; RCA: right coronary artery. C, Quartiles of age-adjusted coronary calcium score in wine drinkers and abstainers. Total calcium score was significantly greater in RW drinkers compared to abstainers (144.4 \pm 362.2 vs $122.0 \pm 370.3$ Agatston units, respectively; chi-square test, $\mathrm{P}<0.001$ ). Significantly greater percentage of individuals with no calcium was observed among abstainers (in green). together with age, was the only variable consistently associated with plaque burden in the multivariate analysis. Such interpretation, however, requires caution, because other lifestyle variables might also have interfered. For instance, drinkers also exercised more. On the other hand, higher fiber consumption as well as ingestion of fewer calories may be viewed as protective for abstainers; but they were more sedentary.

Hence, the hypothesis that RW had a truly protective effect on plaque burden remains speculative - possible, but unproven, in this specific setting. In fact, in the logistic regression multivariate analysis, only glucose level and age were related to the presence of coronary lesions greater than $50 \%$; as seen earlier, lower fasting glucose is attributable to RW.

A higher calcium score among RW drinkers is intriguing. Arterial calcification is a complex phenomenon, generally considered a late event in atherosclerotic plaque evolution. Mintz et al. (23), who studied 1442 patients with the use of coronary intravascular ultrasound and quantitative angiography, observed that calcification does not correlate with lumen size, is less common in acute coronary syndromes, but increases with patient age. Indeed, Burke et al. (24) analyzed human specimens of coronary arteries from patients with extensive CAD and observed that severe calcifications were associated with healed ruptures and that calcification is not associated with plaque instability; also, calcification is universally associated with macrophage infiltration. They concluded that calcification is largely a secondary process. Elevated $\mathrm{Ca}^{2+}$ scores have been consistently associated with $\mathrm{CV}$ events (25). However, $\mathrm{Ca}^{2+}$ scores have not been consistently associated with alcohol consumption (26). Both Tofferi et al. (27), who studied 731 subjects without known coronary disease by electron beam computed tomography, and McClelland et al. (26), who in the MESA study evaluated 6814 subjects over a 2- to 4-year period, did not find any association between alcohol consumption and $\mathrm{Ca}^{2+}$ scores. It is noteworthy that $\mathrm{Ca}^{2+}$ scores in our patients only modestly increased and that, by logistic regression analysis, only $\mathrm{RW}$ was associated with coronary artery calcium $(\mathrm{CAC})>100$. However, there

Table 2. Arterial reactivity and carotid study.

\begin{tabular}{lcc}
\hline & Red wine & Abstainers \\
\hline Brachial artery & & 104 \\
$\quad$ Number & 101 & $4.15 \pm 6.13$ \\
FMD (\%) & $3.13 \pm 12.00$ & $18.80 \pm 8.77$ \\
$\quad$ Nitrate dilatation (\%) & $18.48 \pm 8.36$ & \\
Carotid arteries - IMT & & $0.75 \pm 0.72$ \\
$\quad$ Left carotid (mm) & $0.73 \pm 1.14$ & $0.70 \pm 0.16$ \\
$\quad$ Right carotid (mm) & $0.70 \pm 0.14$ & 5 \\
Plaque (\%) & 6 & 5 \\
\hline
\end{tabular}

FMD: flow mediated dilatation; IMT: intima/media thickness. There were no significant differences between groups ( $t$-test for FMD and IMT; chi-square test for plaque). 
Table 3. Laboratory tests.

\begin{tabular}{|c|c|c|c|}
\hline Variable & Red wine & Abstainers & $\mathrm{P}$ \\
\hline Number & 101 & 104 & \\
\hline Hemoglobin (g/dL) & $14.9 \pm 1.0$ & $15.0 \pm 0.9$ & ns \\
\hline Hematocrit (\%) & $43.8 \pm 2.9$ & $43.6 \pm 3.7$ & ns \\
\hline Platelets $\left(10^{3} / \mathrm{mm}^{3}\right)$ & $209.5 \pm 48.7$ & $244.5 \pm 209.2$ & ns \\
\hline Leucocytes $\left(10^{3} / \mathrm{mm}^{3}\right)$ & $6.2 \pm 1.6$ & $6.2 \pm 1.7$ & ns \\
\hline Glucose (mg/dL) & $97.6 \pm 18.2$ & $105.9 \pm 32.0$ & 0.0245 \\
\hline Total cholesterol (mg/dL) & $192.3 \pm 18,2$ & $184.7 \pm 29.6$ & 0.0017 \\
\hline HDL-cholesterol (mg/dL) & $46.9 \pm 10.9$ & $39.5 \pm 9.0$ & 0.0001 \\
\hline LDL-cholesterol (mg/dL) & $124.6 \pm 30.7$ & $118.4 \pm 28.5$ & ns \\
\hline Triglycerides (mg/dL) & $140.0 \pm 65.6$ & $135.6 \pm 81.7$ & ns \\
\hline Triglycerides/HDL-cholest ratio & $3.2 \pm 1.9$ & $3.9 \pm 3.2$ & 0.0586 \\
\hline Creatinine (mg/dL) & $1.03 \pm 0.16$ & $1.10 \pm 0.22$ & 0.0092 \\
\hline Urea $(\mathrm{mg} / \mathrm{dL})$ & $36.4 \pm 10.6$ & $38.0 \pm 13.0$ & ns \\
\hline AST $(U / L)$ & $25.2 \pm 10.6$ & $24.4 \pm 10.2$ & ns \\
\hline $\operatorname{ALT}(\mathrm{U} / \mathrm{L})$ & $48.9 \pm 17.4$ & $45.1 \pm 16.6$ & ns \\
\hline$\gamma-\mathrm{GT}(\mathrm{U} / \mathrm{L})$ & $53.6 \pm 41.3$ & $47.8 \pm 44.2$ & 0.0316 \\
\hline Alkaline phosphatase (U/L) & $76.1 \pm 15.3$ & $81.9 \pm 22.4$ & 0.0104 \\
\hline Bilirubin total (mg/dL) & $0.72 \pm 0.27$ & $0.66 \pm 0.33$ & ns \\
\hline Bilirubin direct (mg/dL) & $0.12 \pm 0.11$ & $0.10 \pm 0.04$ & ns \\
\hline C-reactive protein $(\mathrm{mg} / \mathrm{L})$ & $2.05 \pm 3.17$ & $2.88 \pm 4.42$ & ns \\
\hline $\mathrm{PSA}(\mathrm{ng} / \mathrm{mL})$ & $1.72 \pm 1.32$ & $1.67 \pm 1.81$ & ns \\
\hline
\end{tabular}

AST: aspartate aminotransferase; ALT: alanine aminotransferase; $\gamma$-GT: gamma glutamyl transferase; PSA: prostatic serum antigen; ns: not significant. The $t$-test was used for statistical analyses.

were several baseline differences between the groups, such as education, smoking, exercise, and diet, which were confounding factors that may have interfered with the results. Therefore, although the finding of higher calcification among drinkers deserves to be noted, no conclusion regarding its mechanistic implications can be drawn.

FMD was not different between the two groups. Karatzi et al. (12), in a review of postprandial and short-term effects of RW on endothelial function, considered the results inconclusive. Similarly, IMT was not different among the groups. This is in contrast to the Cardiovascular Health Study (11) findings in 5888 older adults, for whom consumption of one to six drinks per week had an inverse association with carotid atherosclerosis while consumption of 14 or more drinks was associated with more atherosclerosis. Differences in populations, types of beverages, and number of participants may account for these discrepancies.

Diet and other lifestyle characteristics may influence the relationship of RW intake and its vascular effects; hence they were examined specifically. In general, compared to abstainers, drinkers reported higher caloric intake, especially due to proteins and fats. They were richer, more educated, and exercised more, and they had higher TC mainly due to HDL cholesterol and lower plasma glucose. They also reported less history of diabetes, but among them there were more ex-smokers. Notably, all demographic variables were well matched between the groups, including psychological profile.

Among these findings, higher HDL and lower history of diabetes, as well as lower plasma glucose, can be attributed to RW consumption. Higher HDL has been consistently observed in clinical studies of alcohol consumption (28) and attributed partially to alcohol itself. In addition, polyphenols such as resveratrol (RS), present in RW, also can increase HDL (29). Moreover, many drinkers in our study had a history of long exercise practice, which may also contribute to increased HDL. $\mathrm{HDL}$ is protective against atherosclerosis, especially for its role in reverse cholesterol transport.

Having less of a history of diabetes and lower fasting plasma glucose are also consistent with previous studies, as shown in the metanalysis by Baliunas et al. (30). RS, the most active flavonol of RW, and other flavonols, act as antidiabetics. Flavonoids increase insulin sensitivity in animals (8) and humans (30). RS specifically improves glucose homeostasis in mice (8), improves energy balance, and increases mitochondrial function (31). It also increases survival and insulin sensitivity in mice on a high-calorie diet (9). Ramadori et al. (32) reported that intracerebral infusion of RS normalized hyperglycemia and improved 
Table 4. Social and educational characteristics and daily food intake.

\begin{tabular}{|c|c|c|c|}
\hline Variable & Red wine & Abstainers & $\mathrm{P}$ \\
\hline Number & 101 & 104 & \\
\hline Income $^{a}$ & & & $<0.0001$ \\
\hline$<5$ minimum wage & 5 & 32 & \\
\hline 5-10 minimum wage & 11 & 21 & \\
\hline$>10$ minimum wage & 83 & 51 & \\
\hline Refuse to mention & 1 & 0 & \\
\hline Educational level ${ }^{a}$ & & & 0.0001 \\
\hline Illiterate & 0 & 1 & \\
\hline Incomplete basic first degree & 1 & 7 & \\
\hline Basic (first 4 years, first degree) & 1 & 12 & \\
\hline High school & 9 & 22 & \\
\hline Incomplete College & 9 & 2 & \\
\hline College & 80 & & \\
\hline Physical activity ${ }^{a}$ & & & 0.0002 \\
\hline Sedentarism & 27 & 58 & \\
\hline$<150 \mathrm{~min} /$ week & 17 & 11 & \\
\hline$>150 \mathrm{~min} /$ week & 56 & 35 & \\
\hline \multicolumn{4}{|l|}{$\operatorname{Diet}^{\mathrm{b}}$} \\
\hline Caloric intake (kcal) & $2127.9 \pm 387.7$ & $1836.0 \pm 305.0$ & 0.0001 \\
\hline Carbohydrates (g) & $244.3 \pm 53.9$ & $254.3 \pm 59.5$ & 0.140 \\
\hline Proteins $(\mathrm{g})$ & $96.5 \pm 25.7$ & $88.3 \pm 24.9$ & 0.049 \\
\hline Total fat $(\mathrm{g})$ & $65.8 \pm 25.7$ & $53.0 \pm 17.3$ & $<0.0001$ \\
\hline Saturated fat $(\mathrm{g})$ & $21.9 \pm 10.2$ & $17.3 \pm 6.4$ & $<0.0001$ \\
\hline Polyunsaturated fat (g) & $9.4 \pm 4.5$ & $7.5 \pm 4.0$ & 0.0009 \\
\hline Monounsaturated fat $(\mathrm{g})$ & $20.1 \pm 9.3$ & $16.0 \pm 7.2$ & 0.0005 \\
\hline Cholesterol (g) & $261.9 \pm 131.2$ & $226.6 \pm 118.5$ & 0.041 \\
\hline Dietary fiber $(\mathrm{g})$ & $19.6 \pm 6.4$ & $22.6 \pm 7.0$ & 0.052 \\
\hline Alcohol (g) & $25.1 \pm 17.1$ & & \\
\hline
\end{tabular}

The ${ }^{a}$ chi-square test and the ${ }^{b} t$-test were used for statistical analyses.

hyperinsulinemia in mice with diet-induced diabetes; all these actions are mediated by activating SIRT 1 expressed in several tissues including the brain. In humans, Brasnyo et al. (33) studied 19 patients with type 2 diabetes and showed that RS significantly decreased insulin resistance and increased AKT phosphorylation, which is an essential step in insulin signaling interfering directly in glycogen synthesis. Overall, the above-mentioned studies highlight mechanisms through which RW flavonols may indeed protect against diabetes development.

Finally, RW ingestion remained within recommended doses, i.e., corresponding to about $25 \mathrm{~g} /$ day of alcohol; and, notably, liver enzymes were normal despite an average 18 years of wine drinking, indicating safety of the habit.

\section{Limitations}

Our study has several limitations. First, only healthy, mostly Caucasian men were included; they were not randomly chosen but rather volunteered to participate in the study, which may itself represent a bias. For instance,
RW drinkers belonged to wine brotherhoods and abstainers belonged to churches; they not only did not drink any alcohol but also maintained their own lifestyle. Hence, the findings cannot be extrapolated to the general population. Second, much of the information was self-reported and thus also may be biased. Third, the number of participants was small due mainly to difficulties in recruiting. Finally, long-term use of RW seems to be part of an atypical lifestyle of which drinking is only a component. In this respect, perfect controls would be individuals with similar diets and other lifestyle characteristics; in practice, those are hard, if not impossible, to find.

On the other hand, the study adds broad information regarding past medical history, risk factors, education, income, exercise, diet, psychological profile, and numerous metabolic variables for both abstainers and habitual RW drinkers. For instance, it documents the safety of long-term, moderate, RW drinking. Therefore, it sheds light on the complex interactions of lifestyle factors influencing coronary atherosclerosis.

Some findings in this study are particularly relevant to 
the action of RW: increased coronary calcification but similar plaque burden among drinkers compared to abstainers, increased HDL, and low plasma glucose. As discussed earlier, these may play pivotal roles in the pathophysiology of coronary lesions. However, given the complexity of the mechanisms involved, a clinical randomized trial is warranted in order to definitely establish the

\section{References}

1. Renaud S, de Lorgeril M. Wine, alcohol, platelets, and the French paradox for coronary heart disease. Lancet 1992; 339: 1523-1526, doi: 10.1016/0140-6736(92)91277-F.

2. Mukamal KJ, Jensen MK, Gronbaek M, Stampfer MJ, Manson JE, Pischon T, et al. Drinking frequency, mediating biomarkers, and risk of myocardial infarction in women and men. Circulation 2005; 112: 1406-1413, doi: 10.1161/ CIRCULATIONAHA.105.537704.

3. Ronksley PE, Brien SE, Turner BJ, Mukamal KJ, Ghali WA. Association of alcohol consumption with selected cardiovascular disease outcomes: a systematic review and metaanalysis. BMJ 2011; 342: d671, doi: 10.1136/bmj.d671.

4. Di Castelnuovo A, Rotondo S, lacoviello L, Donati MB, de Gaetano G. Meta-analysis of wine and beer consumption in relation to vascular risk. Circulation 2002; 105: 2836-2844, doi: 10.1161/01.CIR.0000018653.19696.01.

5. Bryson CL, Mukamal KJ, Mittleman MA, Fried LP, Hirsch $\mathrm{CH}$, Kitzman DW, et al. The association of alcohol consumption and incident heart failure: the Cardiovascular Health Study. J Am Coll Cardiol 2006; 48: 305-311, doi: 10.1016/j.jacc.2006.02.066.

6. Opie LH, Lecour S. The red wine hypothesis: from concepts to protective signalling molecules. Eur Heart $J$ 2007; 28: 1683-1693, doi: 10.1093/eurheartj/ehm149.

7. da Luz PL, Serrano Junior CV, Chacra AP, Monteiro HP, Yoshida VM, Furtado $\mathrm{M}$, et al. The effect of red wine on experimental atherosclerosis: lipid-independent protection. Exp Mol Pathol 1999; 65: 150-159, doi: 10.1016/S00144800(99)80004-5.

8. Baur JA, Sinclair DA. Therapeutic potential of resveratrol: the in vivo evidence. Nat Rev Drug Discov 2006; 5: 493-506, doi: $10.1038 / \mathrm{nrd} 2060$.

9. Baur JA, Pearson KJ, Price NL, Jamieson HA, Lerin C, Kalra A, et al. Resveratrol improves health and survival of mice on a high-calorie diet. Nature 2006; 444: 337-342, doi: 10.1038/nature05354.

10. da Luz PL, Tanaka L, Brum PC, Dourado PM, Favarato D, Krieger JE, et al. Red wine and equivalent oral pharmacological doses of resveratrol delay vascular aging but do not extend life span in rats. Atherosclerosis 2012; 224: 136-142, doi: 10.1016/j.atherosclerosis.2012.06.007.

11. Mukamal KJ, Kronmal RA, Mittleman MA, O'Leary DH, Polak JF, Cushman M, et al. Alcohol consumption and carotid atherosclerosis in older adults: the Cardiovascular Health Study. Arterioscler Thromb Vasc Biol 2003; 23: 2252-2259, doi: 10.1161/01.ATV.0000101183.58453.39.

12. Karatzi K, Karatzis E, Papamichael C, Lekakis J, Zampelas A. Effects of red wine on endothelial function: postprandial studies vs clinical trials. Nutr Metab Cardiovasc Dis 2009; 19: 744-750, doi: 10.1016/j.numecd.2009.04.006. role of RW in the evolution of atherosclerosis.

\section{Acknowledgements}

Research supported by Fundação Zerbini, SP, Brazil, FAPESP (\#2012/00329-0), and Banco Bradesco S.A.

13. Motoyama S, Sarai M, Harigaya H, Anno H, Inoue K, Hara $\mathrm{T}$, et al. Computed tomographic angiography characteristics of atherosclerotic plaques subsequently resulting in acute coronary syndrome. J Am Coll Cardiol 2009; 54: 49-57, doi: 10.1016/j.jacc.2009.02.068.

14. Klatsky AL, Friedman GD, Armstrong MA, Kipp H. Wine, liquor, beer, and mortality. Am J Epidemiol 2003; 158: 585595, doi: 10.1093/aje/kwg184.

15. Naumann VJ, Byrne GJ. WHOQOL-BREF as a measure of quality of life in older patients with depression. Int Psychogeriatr 2004; 16: 159-173, doi: 10.1017/S1041610 204000109.

16. Ludwing MWB, Bortolon C, Bertolini M. Ansiedade, depressão e estresse em pacientes com síndrome metabólica. Arq Bras Psicol 2012; 64: 31-46.

17. Caprara GV, Barbaranelli C. Validation of the Comrey Personality Scales on an Italian sample. J Res Pers 1992; 26: 21-31, doi: 10.1016/0092-6566(92)90056-A.

18. Kabacoff RI, Segal DL, Hersen M, Van Hasselt V. Psychometric properties and diagnostic utility of the Beck Anxiety Inventory and the State-Trait Anxiety Inventory with older adult psychiatric outpatients. J Anxiety Disord 1997; 11: 33-47, doi: 10.1016/S0887-6185(96)00033-3.

19. Buzzard M. 24-Hour dietary recall and food record methods. In: Willett W (Editor), Nutritional epidemiology. 2nd edn. New York: Oxford University Press; 1988. p 50-73.

20. Coimbra SR, Lage SH, Brandizzi L, Yoshida V, da Luz PL. The action of red wine and purple grape juice on vascular reactivity is independent of plasma lipids in hypercholesterolemic patients. Braz J Med Biol Res 2005; 38: 1339-1347, doi: 10.1590/S0100-879X2005000900008.

21. Lang RM, Bierig M, Devereux RB, Flachskampf FA, Foster E, Pellikka PA, et al. Recommendations for chamber quantification: a report from the American Society of Echocardiography's Guidelines and Standards Committee and the Chamber Quantification Writing Group, developed in conjunction with the European Association of Echocardiography, a branch of the European Society of Cardiology. J Am Soc Echocardiogr 2005; 18: 1440-1463, doi: 10.1016/j.echo.2005.10.005.

22. Dewey M, Zimmermann E, Deissenrieder F, Laule M, Dubel HP, Schlattmann P, et al. Noninvasive coronary angiography by 320-row computed tomography with lower radiation exposure and maintained diagnostic accuracy: comparison of results with cardiac catheterization in a head-to-head pilot investigation. Circulation 2009; 120: 867-875, doi: 10.1161/ CIRCULATIONAHA.109.859280.

23. Mintz GS, Pichard AD, Popma JJ, Kent KM, Satler LF, Bucher TA, et al. Determinants and correlates of target lesion calcium in coronary artery disease: a clinical, 
angiographic and intravascular ultrasound study. J Am Coll Cardiol 1997; 29: 268-274, doi: 10.1016/S07351097(96)00479-2.

24. Burke AP, Weber DK, Kolodgie FD, Farb A, Taylor AJ, Virmani R. Pathophysiology of calcium deposition in coronary arteries. Herz 2001; 26: 239-244, doi: 10.1007/ PL00002026.

25. Scheuner MT, Setodji CM, Pankow JS, Blumenthal RS, Keeler E. General Cardiovascular Risk Profile identifies advanced coronary artery calcium and is improved by family history: the multiethnic study of atherosclerosis. Circ Cardiovasc Genet 2010; 3: 97-105, doi: 10.1161/CIRCGEN ETICS.109.894527.

26. McClelland RL, Bild DE, Burke GL, Mukamal KJ, Lima JA, Kronmal RA. Alcohol and coronary artery calcium prevalence, incidence, and progression: results from the MultiEthnic Study of Atherosclerosis (MESA). Am J Clin Nutr 2008; 88: 1593-1601, doi: 10.3945/ajcn.2008.26420.

27. Tofferi JK, Taylor AJ, Feuerstein IM, O'Malley PG. Alcohol intake is not associated with subclinical coronary atherosclerosis. Am Heart $J$ 2004; 148: 803-809, doi: 10.1016/ j.ahj.2004.05.023.

28. Brien SE, Ronksley PE, Turner BJ, Mukamal KJ, Ghali WA. Effect of alcohol consumption on biological markers associated with risk of coronary heart disease: systematic review and meta-analysis of interventional studies. BMJ 2011; 342: d636, doi: 10.1136/bmj.d636.

29. Guarente L. Franklin H. Epstein Lecture: Sirtuins, aging, and medicine. N Engl J Med 2011; 364: 2235-2244, doi: 10.1056/NEJMra1100831.

30. Baliunas DO, Taylor BJ, Irving H, Roerecke M, Patra J, Mohapatra S, et al. Alcohol as a risk factor for type 2 diabetes: A systematic review and meta-analysis. Diabetes Care 2009; 32: 2123-2132, doi: 10.2337/dc09-0227.

31. Lagouge M, Argmann C, Gerhart-Hines Z, Meziane H, Lerin C, Daussin F, et al. Resveratrol improves mitochondrial function and protects against metabolic disease by activating SIRT1 and PGC-1alpha. Cell 2006; 127: 1109-1122, doi: 10.1016/j.cell.2006.11.013.

32. Ramadori G, Gautron L, Fujikawa T, Vianna CR, Elmquist JK, Coppari R. Central administration of resveratrol improves diet-induced diabetes. Endocrinology 2009; 150: 5326-5333, doi: 10.1210/en.2009-0528.

33. Brasnyo P, Molnar GA, Mohas M, Marko L, Laczy B, Cseh $\mathrm{J}$, et al. Resveratrol improves insulin sensitivity, reduces oxidative stress and activates the Akt pathway in type 2 diabetic patients. $B r J$ Nutr 2011; 106: 383-389, doi: 10.1017/S0007114511000316. 